\title{
RECTAL GONORRHOEA IN WOMEN*
}

\author{
BY \\ TAGE JENSEN \\ From the Municipal Free Out-patient Clinic for Venereal Diseases, Copenhagen
}

Rectal gonorrhoea in women has always interested venereologists-especially, perhaps, in the pre-penicillin era. This "complication" was known to be less infrequent than it appeared from clinical observation. In many cases the infection pursued a course with rather vague symptomsoften even with no symptoms whatever, but the significance of the proctitis was fully recognized as the latent focus from which re-infection of the urethra and cervix might not infrequently take place. It now appears, however, that penicillin therapy has in some degree reduced the interest taken in this condition, and that clinicians are inclined to conclude from the very favourable effects of penicillin on the uro-genital infection that it has a similar effect on rectal infection. It seems appropriate to raise the question whether this optimistic viewpoint is indeed justifiable.

The more recent investigations reported by Hagerman (1946), and subsequently confirmed by Miescher (1949), Nicol (1948), and Turell (1950), appear rather alarming. In view of the fact that the rectal flora contain very large amounts of bacteria capable of forming penicillinase-an enzyme that destroys the effect of penicillinit is assumed that this substance might be produced in amounts sufficient to compromise the penicillin therapy. This assumption appears to have found clinical support in an account of the effect of penicillin therapy on female gonorrhoea published from the St. Görans Sjukhus, Stockholm (Hagerman, 1946), which shows that no less than 60 per cent. of women admitted with ano-rectal gonorrhoea had a relapse after penicillin therapy (300,000 I.U.), while the percentage of relapse for the entire female material (including the cases of proctitis) was only 15 per cent. So far no publication has contradicted this assertion.

\section{Present Investigations}

Material.-The studies here reported were carried out between August, 1950, and December 31, 1952, in a public, free out-patient clinic for venereal diseases in

\footnotetext{
${ }^{*}$ Received for publication June 4, 1953.
}

Copenhagen (Norrebrogade 18A). They comprise exclusively ambulatory patients, preponderantly young unmarried working-class women. In every case the diagnosis of gonorrhoea was verified by culturing from the urethra (U), cervix (C), and rectum (R). The cultures were all examined at the Statens Seruminstitut, Copenhagen.

Technique.-Cultures from the rectum were taken from the anterior wall, which was pushed outwards through the anus by crooking the index finger introduced into the vagina.

Treatment.-This consisted of a single injection of procaine penicillin (300,000 I.U.).

The criterion of recovery was three negative cultures at weekly intervals.

At the first consultation the patients were instructed, as laid down by the law in Denmark, to abstain from sexual intercourse.

\section{Results}

Frequency of Rectal Gonorrhoea in Women.-The cases with negative rectal cultures but with positive cultures from urethra, cervix, or both totalled 142 ; those with positive rectal cultures totalled 63 , making 205 cases in all. Thus rectal gonorrhoea was demonstrated in 31 per cent. of these 205 patients.

Effect of Penicillin Therapy.-For various reasons it was found impracticable to carry through the desired observations (at least three negative control examinations) in every case. Some patients failed to return for further treatment to this clinic but kept up treatment and observation in some other municipal clinic. As will be noticed, the follow-up observations are much the same in the two groups of patients (Table I).

The relapse : re-infection rate was 6 per cent. for uro-genital gonorrhoea, and 11 per cent. for urogenito-rectal gonorrhoea, a difference of no statistical significance. Both percentages would probably have been higher if all patients had turned up for full control examinations. 
Conclusion.--In contrast to previous investigators, the writer has been unable to demonstrate that rectal gonorrhoea in women is less susceptible to penicillin therapy than uro-genital gonorrhoea.

\section{Positive Gonococcal Cultures found after Penicillin Treatment (relapse : re-infection)}

The distinction between relapse and re-infection after penicillin treatment for gonorrhoea (Table I) is very difficult, especially in out-patients.

\section{TABLE I}

CONTROL CULTURES AFTER TREATMENT WITH PENICILLIN

\begin{tabular}{c|c|c}
\hline $\begin{array}{c}\text { No. of Negative } \\
\text { Cultures }\end{array}$ & $\begin{array}{c}\text { No. of Cases of } \\
\text { Uro-genital } \\
\text { Gonorrhoea }\end{array}$ & $\begin{array}{c}\text { No. of Cases of } \\
\text { Uro-genito-rectal } \\
\text { Gonorrhoea }\end{array}$ \\
\hline 0 & 15 & 5 \\
1 & 6 & 3 \\
2 & 11 & 5 \\
3 & 99 & 42 \\
4 & 2 & $7(11 \%)$ \\
\hline Relapse : re-infection & $9(6 \cdot 3 \%)$ & 63 \\
\hline Total $\ldots$ & 142 & 1 \\
\hline
\end{tabular}

Table II shows that, in four out of the seven cases, the interval between treatment and the control examination at which the presence of gonococci was demonstrated anew was so long as to render re-infection more likely than relapse. This view was supported by two of three patients who were questioned about the matter.

TABLE II

ANALYSIS OF URO-GENITAL-RECTAL CASES WITH POSITIVE GONOCOCCAL FINDINGS AFTER TREATMENT WITH PENICILLIN

\begin{tabular}{|c|c|c|c|c|c|c|}
\hline \multirow[t]{2}{*}{$\begin{array}{c}\text { Record } \\
\text { No. }\end{array}$} & \multirow{2}{*}{$\begin{array}{l}\text { Interval between } \\
\text { Penicillin } \\
\text { Treatment and } \\
\text { Positive } \\
\text { Gonococcal } \\
\text { Findings at } \\
\text { Control } \\
\text { Examination }\end{array}$} & \multirow{2}{*}{$\begin{array}{c}\text { Possibility } \\
\text { of Re- } \\
\text { infection } \\
\text { Admitted }\end{array}$} & \multicolumn{3}{|c|}{$\begin{array}{l}\text { Cultural } \\
\text { Findings at } \\
\text { Control } \\
\text { Examination }\end{array}$} & \multirow[t]{2}{*}{ Conclusion } \\
\hline & & & $\begin{array}{l}\text { Ure- } \\
\text { thra }\end{array}$ & $\begin{array}{l}\text { Cer- } \\
\text { vix }\end{array}$ & $\begin{array}{l}\text { Rec- } \\
\text { tum }\end{array}$ & \\
\hline 521,50 & 1 week & * & - & - & + & Relapse \\
\hline 569.50 & 1 week & $*$ & + & + & - & Re-infection \\
\hline $581 / 50$ & 10 days & Yes & + & + & - & Re-infection \\
\hline 13,51 & 1 month & Yes & + & + & - & Re-infection \\
\hline 1251 & 3 weeks & $*$ & + & + & - & Re-infection \\
\hline $475 / 51$ & 41 days & No & + & + & - & Re-infection \\
\hline $66 / 52$ & 5 weeks & * & + & + & + & Re-infection \\
\hline
\end{tabular}

* Not questioned
Furthermore, rectal cultures in five out of seven cases were negative, which was not to be expected if there had been a relapse resulting from insufficient penicillin-therapy with re-infection of the urogenital organs from refractory rectal gonorrhoea. Thus relapse probably occurred in one case only.

Unfortunately six of these seven patients failed to return to the clinic, so that the result of re-treatment with the same dosage of penicillin is available in only one case, in which three negative cultural findings from the urethra, cervix, and rectum, were demonstrated at intervals of one week.

\section{Pathogenesis of Rectal Gonorrhoea in Women}

It has been generally assumed that the rectal infection originates from infective secretion from the uro-genital area. It is highly questionable, however, whether this conclusion-based on the close anatomical relationship of the vagina and the anushas been established on sufficient evidence. Thus Pelouze (1939) holds that this theory is refuted, and refers to anatomic-histological conditions which appear to preclude this mechanism of infection (length of the anal canal, lining of this canal with a stratified squamous epithelium, tonic contraction of the sphincters). He can see no explanation of the occurrence of rectal gonorrhoea in women except the assumption that the infection is due to infected instruments, explorative finger-stalls, thermometers, nozzles of irrigating syringes, etc. A more " biological" source of infection appears to be rather foreign to the Anglo-American trend of thought.

Table III shows that over one-half of the patients questioned admitted having had peno-anal contact with a partner, who may thus have either transmitted gonococci to the female rectum from her own uro-genital infection, or infected both sites. It is reasonable to assume that at least some of the individuals questioned failed to give correct information, whereas others were not able to give any information on account of inebriation at the time of coitus (listed in Table III under "denied"). Therefore it is probable that the great majority, perhaps all, of these cases of rectal gonorrhoea in women originated through peno-anal contact and occurred simultaneously with their uro-genital infection.

TABLE III

PATHOGENESIS OF RECTAL GONORRHOEA IN FEMALES

\begin{tabular}{c|c|c|c}
\hline $\begin{array}{c}\text { No. of Patients } \\
\text { with Rectal } \\
\text { Gonorrhoea }\end{array}$ & \multicolumn{2}{|c|}{ Rectal Coitus } & $\begin{array}{c}\text { Patients not } \\
\text { Questioned }\end{array}$ \\
\hline 63 & $-\frac{\text { Admitted }}{25}$ & Denied & \\
\hline 63 & 25 & 20 & 18 \\
\hline
\end{tabular}

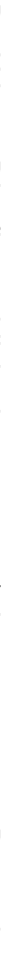




\section{Combination of Rectal and Uro-genital Gonorrhoea}

From Tables I and IV it is evident that isolated rectal gonorrhoea in women is relatively rare (6 per cent. of all the gonorrhoeal, proctal, and procto-urethro-cervical infections, and only about 2 per cent. of the 205 cases of female gonorrhoea studied).

The fact that rectal gonorrhoea is nearly always combined with urethral, cervical, or urethrocervical gonorrhoea suggests that peno-anal coitus has been performed intermittently with normal coitus. Most likely the normal performance of

TABLE IV

LOCATION OF GONOCOCCI IN FEMALE URO-GENITALRECTAL GONORRHOEA

\begin{tabular}{|c|c|c|c|c|c|}
\hline \multicolumn{5}{|c|}{ Gonococci Demonstrated by Culture from } & \multirow{2}{*}{$\frac{\text { No. of Cases }}{4}$} \\
\hline Rectum only .. & . & . & . & . & \\
\hline Rectum + cervix & . & . & . & . & 6 \\
\hline Rectum + urethra & .. & $\cdots$ & . & . & 4 \\
\hline \multicolumn{3}{|c|}{ Rectum + urethra + cervix } & $\therefore$ & .. & 49 \\
\hline Total .. & .. & . & . & . & 63 \\
\hline
\end{tabular}

coitus is followed by the peno-anal form as an anticonceptional measure rather than a sexual perversion.

\section{Summary}

(1) Rectal gonorrhoea was found in 31 per cent. of women with uro-genital gonorrhoea.

(2) Treatment with penicillin in the usual dosage $(300,000$ I.U. procaine penicillin) proved as effective in rectal as in uro-genital infection.

(3) Analysis of the relapse : re-infection cases shows that the percentage of relapse in the patients with rectal gonorrhoea was low.

(4) Isolated rectal gonorrhoea was found in only four out of 63 cases, and peno-anal coitus seems to be the predominant cause of rectal gonorrhoea in women.

\section{REFERENCES}

Hagerman, G. (1946). Förh. XI nord. derm. Fören. Stockholm. Miescher, G. (1949). Arch. Derm. Syph., Berl., 189, 14.

Nicol, C S. (1948), British Journal of Venereal Diseases, 24, 26.

Pelouze, P. S. (1939). " "Gonorrhea in the Male and Female," 3rd ed. Saunders, Philadelphia.

Turell, R. (1950). Amer. J. Dis. Child., 79, 510. 